\title{
Glycine Catalyzed Synthesis of 3-Indole Derivatives Mediated by PEG-400 in Water
}

\author{
ABDUL AHAD and MAQDOOM FAROOQUI*
}

Post Graduate and Research Centre, Dr. Rafiq Zakaria Campus, Maulana Azad College, Rouza Baugh, Aurangabad(M.S), 431001, India

maqdoomf789@gmail.com

Received 26 November 2015 / Accepted 18 December 2015

\begin{abstract}
Glycine in aqueous polyethylene glycol has been utilized as a highly efficient catalytic medium for the multicomponent synthesis of 3-substituted indoles. This protocol provides a convenient and environmentally benign access to corresponding 3 - indole derivatives.
\end{abstract}

Keywords: Glycine, PEG-400 in water, 3-Substituted indoles

\section{Introduction}

Indole and its analogues have been found as an essential structural unit in medicinal drugs and in agricultural chemicals with significant physiological activities ${ }^{1}$. Among different indole scaffold containing molecules, 3 -substituted indoles are of greater interest as they are medicinally potent and are the key intermediates for the synthesis of some diverse therapeutic agents ${ }^{2,3}$. The importance of these molecules in the field of medicinal chemistry has invited much more interest of organic chemists to develop new synthetic protocols for the preparation of 3-subtitited indoles. Several muticomponent strategies have been developed for the synthesis of substituted indoles ${ }^{4}$.

However, the development of convenient, simple and greener synthetic techniques remains a provocative task, particularly for the synthesis of 3-substituted indole, which exhibits important building blocks in many synthetic designs. The multicomponent reaction of benzaldehydes, indole and active methylene compounds for the synthesis of 3-substituted indoles has been accomplished in the presence of different catalysts and reagents such as tetrabutylammonium fluoride ${ }^{5}$, copper (II) sulfonato salen complex ${ }^{6}, \mathrm{Zn}$ (salphen) complex ${ }^{7}$, $N, N$ 1-dioxide $\mathrm{Zn}$ (II) complex ${ }^{8}$ and [TBA][Gly] ionic liquid ${ }^{9}$. However some of the protocols have demerits which includes long reaction time, difficult workup, toxic and expensive reagents. To overcome these issues, the development of efficient, clean, feasible and high yielding methods for the synthesis of 3-substituted indoles remains a valid exercise.

$\alpha$ - Amino acids are found as zwitter ions, having amphoteric character and are useful in numerous organic reactions such as coupling reactions, aldol condensations, Mannich type 
reactions and in many asymmetric reactions. Glycine is one of the $\alpha$-amino acids that have many significant roles in organic synthesis but there are very few works which explored the activity of glycine as an organo catalyst ${ }^{10-12}$. It is inexpensive, eco-friendly, non corrosive and readily available.

Recently, the use of PEG-400 in various organic reactions has drawn great attention as it is inexpensive, thermally stable, easy to handle, benign and non volatile reaction media $^{13,14}$. Thus, PEG-400 has come out as an efficient alternate medium for various chemical transformations ${ }^{15-17}$.

The versatile character of glycine and eco-friendly nature of PEG-400 attracted us to couple them together in a same reaction and study their effectiveness for the synthesis of 3 -substituted indoles. Herein, we describe glycine catalyzed multicomponent synthesis of 3 -substiuted indoles mediated by PEG-400 in water as a green solvent system.

\section{Experimental}

Chemicals and solvents were purchased from SD Fine Company. NMR spectra were recorded on a Bruker advance DPX-250. Mass spectra were recorded on Waters LC-MS spectrophotometer. The progress of the reactions and the purity of the products were observed by TLC on silica-gel.

\section{General Procedure for the Synthesis of 3-Substituted Indoles(4a-4g)}

A mixture of aldehyde (1 mmol), malonitrile (1 mmol), glycine (10 wt $\%)$ in PEG-400:Water $(1: 1,4 \mathrm{~mL})$ were taken in a flask and stirred at $50{ }^{\circ} \mathrm{C}$ for $5 \mathrm{~min}$ then indole $(1 \mathrm{mmol})$ was added and stirred at $70{ }^{\circ} \mathrm{C}$. The reaction completion was monitored by TLC. For some products, the reaction mixture was cooled to room temperature and poured in ice cold water. The obtained solid product was filtered and washed with water and recrystallized by EtOAc/ $n$-hexane to give pure products. To some products after completion, the reaction mixture was cooled to room temperature and partitioned between ethyl acetate and water. The aqueous and organic layers were then separated and the aqueous layer was extracted by ethyl acetate twice. The combined ethyl acetate extracts were dried over anhydrous $\mathrm{Na}_{2} \mathrm{SO}_{4}$ and concentrated under vacuum to afford the crude compounds which after recrystallization gave pure products.

\section{2-((1H-indol-3-yl)(4-methoxyphenyl)methyl)malononitrile(4b)}

${ }^{1} \mathrm{H}$ NMR (400 MHz, DMSO-d ${ }_{6}$;MS) $\delta=11.20(\mathrm{~s}, 1 \mathrm{H}), 7.55(\mathrm{~d}, 1 \mathrm{H}, \mathrm{J}=2.5 \mathrm{~Hz}), 7.55-$ $7.40(\mathrm{~m}, 4 \mathrm{H}), 7.10(\mathrm{t}, 1 \mathrm{H}, \mathrm{J}=8.2 \mathrm{~Hz}), 6.97-6.92(\mathrm{~m}, 3 \mathrm{H}), 5.78(\mathrm{~d}, 1 \mathrm{H}, \mathrm{J}=9.4 \mathrm{~Hz}), 5.15(\mathrm{~d}$, $1 \mathrm{H}, \mathbf{J}=9.4 \mathrm{~Hz}), 3.73(\mathrm{~s}, 3 \mathrm{H}) \mathrm{ppm}, \mathrm{MS}(\mathrm{m} / \mathrm{z}): 300.1$.

\section{2-((4-Chlorophenyl)(1H-indol-3-yl)methyl)malononitrile(4c)}

${ }^{1} \mathrm{H}$ NMR (400 MHz, DMSO-d 6 ; TMS $)$ ) $\delta=11.26(\mathrm{~s}, 1 \mathrm{H}), 7.56(\mathrm{~d}, 1 \mathrm{H}, \mathrm{J}=2.5 \mathrm{~Hz}), 7.55(\mathrm{~d}, 2 \mathrm{H}$, $\mathrm{J}=8.2 \mathrm{~Hz}), 7.46(\mathrm{~d}, 3 \mathrm{H}, \mathrm{J}=8.5 \mathrm{~Hz}), 7.40(\mathrm{~d}, 1 \mathrm{H}, \mathrm{J}=8.4 \mathrm{~Hz}), 7.11(\mathrm{t}, 1 \mathrm{H}, \mathrm{J}=7.5 \mathrm{~Hz}), 6.99$ $(\mathrm{t}, 1 \mathrm{H}, \mathrm{J}=7.5 \mathrm{~Hz}), 5.87(\mathrm{~d}, 1 \mathrm{H}, \mathrm{J}=9.4 \mathrm{~Hz}), 5.28(\mathrm{~d}, 1 \mathrm{H}, \mathrm{J}=9.4 \mathrm{~Hz}$, ) ppm, MS $(\mathrm{m} / \mathrm{z}): 304.1$.

\section{2-((1H-Indol-3-yl)(4-nitrophenyl)methyl)malononitrile(4f)}

${ }^{1} \mathrm{H}$ NMR (400 MHz, DMSO-d $\mathrm{d}_{6}$;TMS) $\delta=11.33(\mathrm{~s}, 1 \mathrm{H}), 8.27(\mathrm{~d}, 2 \mathrm{H}, \mathrm{J}=8.5 \mathrm{~Hz}), 7.81(\mathrm{~d}, 2 \mathrm{H}$, $\mathrm{J}=8.5 \mathrm{~Hz}), 7.63(\mathrm{~d}, 1 \mathrm{H}, \mathrm{J}=7.2 \mathrm{~Hz}),, 7.49(\mathrm{~d}, 1 \mathrm{H}, \mathrm{J}=7.5 \mathrm{~Hz}), 7.41(\mathrm{~d}, 1 \mathrm{H}, \mathrm{J}=7.5 \mathrm{~Hz}$,$) ,$ $7.10(\mathrm{t}, 1 \mathrm{H}, \mathrm{J}=7.2 \mathrm{~Hz}$ ) $, 6.98(\mathrm{t}, 1 \mathrm{H}, \mathrm{J}=7.2 \mathrm{~Hz}) ,6.00(\mathrm{~d}, 1 \mathrm{H}, \mathrm{J}=8.8 \mathrm{~Hz}),, 5.51(\mathrm{~d}, 1 \mathrm{H}, \mathrm{J}=9.2$ $\mathrm{Hz},) \mathrm{ppm}, \mathrm{MS}(\mathrm{m} / \mathrm{z}): 315.2$. 


\section{2-((1H-Indol-3-yl) (p-tolyl)methyl)malononitrile(4g)}

${ }^{1} \mathrm{H}$ NMR (400 MHz, DMSO-d 6 ;TMS) $\delta=11.22(\mathrm{~s}, 1 \mathrm{H}), 7.55(\mathrm{~d}, 1 \mathrm{H}, \mathrm{J}=2.5 \mathrm{~Hz}), 7.47(\mathrm{~d}, 1 \mathrm{H}, \mathrm{J}$ $=8.2 \mathrm{~Hz}), 7.40(\mathrm{~d}, 3 \mathrm{H}, \mathrm{J}=7.8 \mathrm{~Hz}), 7.17(\mathrm{~d}, 2 \mathrm{H}, \mathrm{J}=8.2 \mathrm{~Hz}), 7.12(\mathrm{t}, 1 \mathrm{H}, \mathrm{J}=7.8 \mathrm{~Hz}), 6.96(\mathrm{t}, 1 \mathrm{H}, \mathrm{J}$ $=7.8 \mathrm{~Hz}), 5.82(\mathrm{~d}, 1 \mathrm{H}, \mathrm{J}=9.5 \mathrm{~Hz}), 5.17(\mathrm{~d}, 1 \mathrm{H}, \mathrm{J}=9.5 \mathrm{~Hz}), 2.27(\mathrm{~s}, 3 \mathrm{H}) \mathrm{ppm}, \mathrm{MS}(\mathrm{m} / \mathrm{z}): 284.2$.

\section{Results and Discussion}

The catalytic potential of glycine was explored for the three component synthesis of 3-substituted indoles in PEG:Water medium(1:1) (Scheme 1). Initially, the optimization of the reaction conditions was performed for the model reaction among 4-chloro benzaldehyde, malonitrile and indole in the presence of $10 \mathrm{~mol} \%$ of glycine in various solvents at room temperature to $100{ }^{\circ} \mathrm{C}$ (Table 1). The results exposed that the product $4 \mathbf{c}$ was obtained in $40 \%$ yield in ethanol at room temperature after $30 \mathrm{~h}$ (Table 1, entry 1), when the temperature of the reaction is increased to $80{ }^{\circ} \mathrm{C}$, no improvement in the yield was observed (Table 1, entry 2). In other solvents, the product $\mathbf{4 c}$ was obtained in poor to moderate yields (Table 1, entries 3, 4). When water and PEG-400 used separately, moderate yields of the corresponding products were observed (Table 1, entries 5,6).

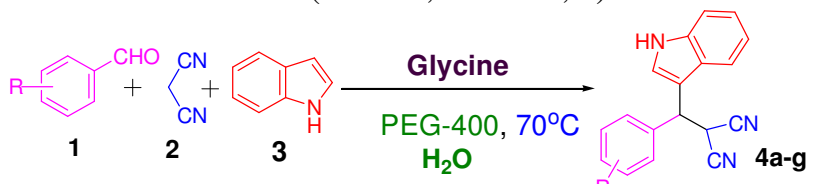

Scheme 1

Table 1. Optimization study of glycine catalyzed synthesis of 3 substituted indoles ${ }^{\mathrm{a}}$

\begin{tabular}{cccccc}
\hline Entry & $\begin{array}{c}\text { Catalyst, } \\
\text { mol\% }\end{array}$ & Solvent & Temperature & $\begin{array}{c}\text { Time, } \\
\text { h }\end{array}$ & $\begin{array}{c}\text { Product, } \\
\mathbf{4 c}^{\mathbf{b}}\end{array}$ \\
\hline 1 & 10 & EtoH & R.T & 30 & 40 \\
2 & 10 & EtoH & 80 & 20 & 38 \\
3 & 10 & toulene & 80 & 10 & 20 \\
4 & 10 & $\mathrm{CH}_{2} \mathrm{Cl}_{2}$ & 40 & 10 & 30 \\
5 & 10 & PEG-400 & 70 & 10 & 35 \\
6 & 10 & Water & 100 & 10 & 40 \\
7 & 10 & PEG:Water & 70 & 3 & 83 \\
8 & 20 & PEG:Water & 70 & 3 & 83 \\
9 & 10 & PEG:Water & 90 & 3 & 75 \\
10 & 10 & PEG:Water & R.T & 10 & 42 \\
\hline
\end{tabular}

${ }^{a}$ Reaction conditions: 4-chloro benzaldehyde $(1 \mathrm{mmol})$, malonitrile $(1 \mathrm{mmol})$ and indole $(1 \mathrm{mmol})$, glycine ( $m o l \%)$, solvent $4 \mathrm{~mL}$. ${ }^{b}$ Isolated yields, R.T=Room Temperature

Surprisingly, when the mixture of PEG-400 and water (1:1) was used, rate of the reaction improved significantly, leading to product $4 \mathbf{c}$ in $83 \%$ yield at $70{ }^{\circ} \mathrm{C}$ (Table 1, entry 7 ). Increase of the catalyst concentration to the same solvent system has no influence in improvement of product formation (Table 1, entry 8). When temperature was increased to $90{ }^{\circ} \mathrm{C}$, the product $4 \mathbf{c}$ was reduced to $75 \%$ whereas at room temperature poor yield was obtained (Table 1, entries 9, 10).

To study the generality of the glycine in aqueous polyethylene glycol mediated protocol, a number of 3-substituted indole derivatives were prepared by using indole, malonitrile and substituted aldehydes through multicomponent reaction and results are given in Table 2, entries 1-7. It was found that different electron withdrawing substituents on the benzene ring of 
aldehydes afforded the corresponding 3-substituted indoles in better to excellent yields. In case of aldehydes having electron releasing groups such as para-methoxy benzaldehyde and ortho methoxy benzaldehyde, the product yields are low (Table 2, entries 2, 5, 7).

Glycine having amphoteric character, thereby promoting the three component condensation reaction through in situ-generated benzylidenemalononitrile via Knoevenagel condensation between malonitrile and aldehyde followed by Michael addition of indole to benzylidenemalononitrile adduct. The catalytic activity of glycine has been enhanced in aqueous polyethylene glycol medium at $70{ }^{\circ} \mathrm{C}$ as compared to other conditions (Table 1 , entries 1-6) and accelerates the conversion of 3-substituted indoles more effectively.

Table 2. Glycine catalyzed synthesis of 3-substituted indoles in PEG-400: Water ${ }^{\mathrm{a}}$

\begin{tabular}{ccccc}
\hline Entry & $\mathrm{R}$ & Product & Time & Yield $^{\mathrm{b}}$ \\
\hline 1 & $\mathrm{H}$ & $\mathbf{4 a}$ & 3 & 80 \\
2 & $4-\mathrm{OMe}$ & $\mathbf{4 b}$ & 4 & 65 \\
3 & $4 \mathrm{Cl}$ & $\mathbf{4 c}$ & 3 & 83 \\
4 & $2 \mathrm{Cl}$ & $\mathbf{4 d}$ & 3 & 82 \\
5 & $2-\mathrm{OMe}$ & $\mathbf{4 e}$ & 4 & 62 \\
6 & $4-\mathrm{NO}_{2}$ & $\mathbf{4 f}$ & 3 & 84 \\
7 & $4-\mathrm{CH}_{3}$ & $\mathbf{4 g}$ & 4 & 76 \\
\hline
\end{tabular}

${ }^{a}$ Reaction condition: indoles $(1 \mathrm{mmol})$, malononitrile $(1 \mathrm{mmol})$, aldehydes $(1 \mathrm{mmol})$, glycine $(10 \mathrm{~mol} \%)$ and PEG-400: Water (1:1,4mL) were stirred at $70^{\circ} \mathrm{C} .{ }^{b}$ Isolated yield

\section{Conclusion}

In summary, we have developed a new, simple and efficient method for the synthesis of 3 -substituted indoles via a three component condensation reaction of aldehydes, malonitrile and indole in PEG-400: Water medium catalyzed by glycine. PEG-400, water and glycine are non-toxic, inexpensive and are readily available. Moreover the protocol offers several other merits such as simple experimentation with easy workup procedure, eco-friendly approach and better yields of the products in short reaction time.

\section{References}

1. (a) Hajicek J, Collect Czech Chem Commun., 2007, 72, 821; DOI:10.1135/cccc20070821 (b) Metwally M A, Shaaban S, Abdel Wahab B F and El-Hiti G A, Curr Org Chem., 2009, 13(14), 1475-1496; DOI:10.2174/138527209789055063 (c) Casapullo A, Bifulco G, Bruno I and Raffaele R, J Nat Prod., 2000, 63(4), 447-451; DOI:10.1021/np9903292

2. Deng J, Sanchez T, Neamat N and Briggs J M, J Med Chem., 2006, 49(5), 16841692; DOI:10.1021/jm0510629

3. Contractor R, Samudio I J, Estrov Z, Harris D, McCubrey J A, Safe S H, Andreeff M and Konopleva M, Cancer Res., 2005, 65(7), 2890-2898; DOI:10.1158/00085472.CAN-04-3781

4. (a) Zhang G W, Wang L, Nie J and Ma J A, Adv Synth Catal., 2008, 350(10), 14571463; DOI:10.1002/adsc.200800239 (b) Renzetti A, Dardennes E, Fontana A, Maria P D, Sapi J and Gerard S, J Org Chem., 2008, 73(17), 6824-6827; DOI:10.1021/jo800529q (c) Shirakawa S and Kobayashi S, Org Lett., 2006, 8(21), 4939-4942; DOI:10.1021/ol062031q (d) Zhao X D, Yu Z K, Xu T Y, Wu P and Yu H F, Org Lett., 2007, 9(25), 5263-5266; DOI:10.1021/ol7024795 (e) Sui Y, Liu L, Zhao J L, Wang D and Chen Y J, Tetrahedron Lett., 2007, 48(22), 3779-3782; DOI:10.1016/j.tetlet.2007.04.002 
5. Singh N, Allam B K, Raghuvanshi D S and Singh K N, Adv Synth Catal., 2013, 355(9), 1840-1848; DOI:10.1002/adsc.201300162

6. Qu Y, Ke F, Zhou L, Li Z, Xiang H, Wu D and Zhou X, Chem Commun., 2011, 47, 3912-3914; DOI:10.1039/C0CC05695B

7. Anselmo D, Adán E C E , Belmonte M M and Kleij A W, Eur J Inorg Chem., 2012, 29, 4694-4700; DOI:10.1002/ejic.201200150

8. Chen W, Cai Y, Fu X, Liu X, Lin L and Feng X, Org Lett., 2011, 13(18), 4910-4913; DOI:10.1021/ol2019949

9. Chinna Rajesh U, Rohit Kholiya, Anuj Thakur and Diwan Rawat S, Tetrahedron Lett., 2015, 56(14), 1790-1793; DOI:10.1016/j.tetlet.2015.02.058

10. Bandita D and Pasha M A, Ultrason Sonochem., 2012, 19(4), 725-728; DOI:10.1016/j.ultsonch.2012.01.006

11. Reddy M B M, Jayashankara V P and Pasha M A, Synth Commun., 2010, 40(19), 2930-2934; DOI:10.1080/00397910903340686

12. Ershov O V, M. Ievlev Yu, Tafeenko V A and Nasakin O E, Green Chem., 2015, 17, 4234-4238; DOI:10.1039/C5GC00909J

13. Wei W, Wang Y H, Jiang J Y and Jin Z L, Chin Chem Lett., 2007, 18(8), 933-935; DOI:10.1016/j.cclet.2007.05.044

14. He F, Li S, Vert M and Zhuo R, Polymer, 2003, 44(18), 5145-5151; DOI:10.1016/S0032-3861(03)00562-7

15. Chhanda M and Tapaswi P K, Tetrahedron Lett., 2008, 49(43), 6237-6240; DOI:10.1016/j.tetlet.2008.08.041

16. Nagaraju A, Ramulu B J, Shukla G, Srivastava A, Verma G K, Raghuvanshi K and Singh M S, Green Chem., 2015, 17(2), 950-958.

17. Nagarapu L, Raghu M and Lingappa Y, Eur J Chem., 2010, 1(3), 228-231; DOI:10.5155/eurjchem.1.3.228-231.172 